PAPER

\title{
Attentional deficits affect activities of daily living in dementia-associated with Parkinson's disease
}

\author{
K Bronnick, U Ehrt, M Emre, P P De Deyn, K Wesnes, S Tekin, D Aarsland

Received 14 March 2006

Revised version received

2 June 2006

Accepted 20 June 2006

Published Online First

24 June 2006

\begin{abstract}
Objective: To investigate the effects of attentional deficits on activities of daily living (ADL) in patients with dementia associated with Parkinson's disease (PDD).

Method: 461 patients were assessed neuropsychologically. Factor analyses were used to differentiate attention from other cognitive functions and to differentiate different aspects of ADL functions. The effects of the attentional measure on $A D L$ were examined using sequential multiple regression, controlling for age, sex, education, severity of motor symptoms and other cognitive functions.

Results: Three cognitive factors were identified, with one factor emerging as a measure of vigilance and focused attention. This factor predicted different aspects of ADL status even after controlling for motor functions and other cognitive factors. The attention factor was the single strongest cognitive predictor of $A D L$ status, matching the strength of the effects of motor functions on ADL status.
\end{abstract}

Conclusion: Impaired attention is an important determinant of ADL functions in patients with PDD. with Parkinson's disease. ${ }^{19}$ However, not much work has been carried out on the effect of changes in vigilance and selective attention. Given the fundamental role of vigilance and selective attention for sustained goal-directed activity and the variable vigilance level of patients with PDD, we hypothesise that vigilance and selective attention, hereby just referred to as "attention", are major factors in explaining ADL deficits.

We are not aware of any previous published studies on the relationship between ADL and attention in patients with PDD, but the trail making $\mathrm{B}$ test $\mathrm{t}^{19}$ and a visuoconstruction task $^{20}$ has been proposed as a major predictor of ADL status in Parkinson's disease. Fluctuating attention among patients with DLB correlates with ADL deficits. ${ }^{21}$ However, these studies have used small samples and limited cognitive testing.

To test the hypothesis that attentional deficit is related to $\mathrm{ADL}$, we investigated the baseline data from a recent study ${ }^{22}$ that investigated the effects of rivastigmine on patients with PDD, in which a large sample of patients with PDD was examined using several cognitive tests, some designed specifically to measure attention. The size of the sample made it possible to choose a factor-analytical approach to generate compound measures that represented the underlying attentional processes better than isolated neuropsychological tests, and to compare the effect of attention with that of other cognitive measures. Thus, our study aimed to investigate the effect of attention on level of ADL functions, and to compare this effect with other cognitive functions and with measures of motor function.

Abbreviations: ADAS-cog, Alzheimer's Disease Assessment Scalecognitive; ADCS-ADL, Alzheimer's Disease Cooperative StudyActivities of Daily Living; $A D L$, activities of daily living; $C D R$, Cognitive Drug Research; DLB, dementia with Lewy bodies; MMSE, Mini-Mental State Examination; PCA, principal component analysis; PDD, dementia associated with Parkinson's disease; UPDRS, Unified Parkinson's Disease Rating Scale
Deficit in executive functions has been proposed as the most important cognitive predictor of ADL deficit in patients 


\section{METHODS \\ Patients}

In all, 541 patients, at least 50 years old, were included in this retrospective analytical study. They were diagnosed with Parkinson's disease according to the clinical diagnostic criteria of the United Kingdom Parkinson's Disease Society Brain Bank ${ }^{23}$ and with PDD according to the fourth edition of the Diagnostic and statistical manual of mental disorders (code 294.1). ${ }^{24}$ Patients had mild to moderately severe dementia as defined by a Mini-Mental State Examination (MMSE) score of 10-24, with the onset of symptoms occurring at least 2 years after the diagnosis of Parkinson's disease.

The care givers and the mentally competent patients, or their legally authorised representative if mentally incompetent, gave informed written consent. Exclusion criteria included the presence of any primary neurodegenerative disorder other than Parkinson's disease or other causes of dementia, a history of a major depressive episode, the presence of an active, uncontrolled seizure disorder, the presence of any disability or unstable disease unrelated to Parkinson's disease, known hypersensitivity to drugs similar to rivastigmine and the use of a cholinesterase inhibitor or anticholinergic drugs during the 4 weeks before inclusion in the study.

Patients were recruited from centres in Austria, Belgium, Canada, France, Germany, Italy, The Netherlands, Norway, Portugal, Spain, Turkey and the UK. Before the study began, the protocol, informed consent form and other information provided to patients and care givers were reviewed by the institutional review board at each centre. All procedures were conducted in accordance with the ethical standards of the responsible committee on human experimentation and with the Declaration of Helsinki as revised in 1983.

\section{MEASURES \\ Cognition}

The MMSE ${ }^{25}$ and the Alzheimer's Disease Assessment Scalecognitive section (ADAS-cog) ${ }^{26}$-were administered, and each of the 11 items on the ADAS-cog and the "Serial 7" task in MMSE were included as separate variables. The first seven items on the ADAS-cog are word recall, commands, constructional praxis, naming objects or fingers, ideational praxis, orientation and word recognition. The last four of the ADAS-cog items are scored according to the judgement of the examiner, on the basis of the observations during the testing procedure, not by direct recording of patient responses. These four scales are remembering test instructions, spoken language ability, word-finding difficulty and comprehension.

The Delis-Kaplan Executive Function System verbal fluency test, which requires patients to produce as many words per minute as they can, starting with a particular letter, with higher scores indicating better performance, ${ }^{27}$ was used for assessing executive functions. The number of correct words, set loss errors and repetition errors were included in the analyses.

The Cognitive Drug Research (CDR) computerised assessment system attention tests were used to assess attention. The three CDR attention tests-namely, simple reaction time, choice reaction time and digit vigilance-take around $7 \mathrm{~min}$ to complete. All tests use visual stimuli, and the patients respond using buttons on a response box that is independent of the keyboard and ensures millisecond accuracy of recording. Reaction times for all tasks were measured in milliseconds, with higher scores indicating poorer attention. ${ }^{8}{ }^{28}$ The digit vigilance test requires a response from the patient whenever a stimulus matches a continuously presented target stimulus. In addition to reaction times, the number of detected targets and false alarms from the digit vigilance task and the response accuracy on the choice reaction time task were included as variables.

All tests were administered during the "ON" phase.

\section{Activities of daily living}

A care giver of the patient filled out the Alzheimer's Disease Cooperative Study-Activities of Daily Living (ADCS-ADL) Scale, for which scores can range from 0 to 78 points, with higher scores indicating better functioning. ${ }^{30}$ For the present study, the total score and each separate item score were included. The individual items were subjected to factor analysis. The ADCS-ADL includes measures of physical ADL skills such as bathing, walking and getting dressed, instrumental ADL skills such as using a telephone or household appliances, and activities such as reading, conversation and watching TV.

\section{Motor symptoms}

Parkinsonism was assessed by means of the motor examination section (part III) of the Unified Parkinson's Disease Rating Scale (UPDRS), for which scores can range from 0 to 108 points, with higher scores indicating more severe motor symptoms. ${ }^{31}$ Before the study was started, investigators received 2 days of training on outcome measures to ensure that test administration was consistent across centres.

\section{Statistical analyses}

Data were analysed with SPSS V.12.02. A factor analysis using principal components factor extraction with varimax rotation $^{32}$ was carried out with the cognitive variables. All three reaction time variables were subjected to a logarithmic transform to correct a positive skew. The Kaiser-Meyer-Olkin measure of sampling adequacy was 0.88 , and Bartlett's test of sphericity was highly significant at $\mathrm{p}<0.001$, indicating that the data were appropriate for principal component analysis (PCA). ${ }^{33}$ The resulting cognitive factors were interpreted by the authors regarding content and named accordingly, with emphasis on identifying the factor with items most clearly measuring attentional components.

The 22 items on the ADCS-ADL were also subjected to PCA with varimax rotation. Although several items were bimodally distributed, they were still included, as non-normality of data in PCA is a problem mainly when testing the significance of factors. ${ }^{33}$ The measure of sampling adequacy was 0.92 and Bartlett's test of sphericity was highly significant at $\mathrm{p}<0.00 \mathrm{l}$, indicating that the ADL data were appropriate for PCA. ${ }^{33}$

For both factor analyses, to identify factors with simple structure, items were deleted from the analysis if the maximal factor loading was $<0.5^{32}$ on any of the factors. The number of factors was determined using the condition that the latent roots (eigenvalues) of each factor should be $>1 .^{32}$ The final factor solution was used to generate new variables containing the factor scores for each factor for every patient. A regression-based approach was used for generating factor scores with maximal correlations with the factors, ${ }^{32}$ resulting in uncorrelated variables with means of 0 and standard deviations (SDs) 1. Additionally, compound scales were generated for the ADCS-ADL by calculating the mean scores of the variables of each factor, thus retaining the clinical interpretability of the ADL scores.

Sequential multiple regression was used to assess the relative effect of cognitive factors on total ADL score and the ADL factors. To control for age, sex and years of completed education, these variables were entered in step 1 of the models. The motor part of UPDRS-III was entered in step 2 to control for the effect of motor function on the cognitive measures. In step 3, non-attentional cognitive measures were entered. In step 4, the measure of attention was entered to 
determine whether attention independently contributed to ADL functions beyond motor functions and other cognitive functions.

The independent variables in the regression analyses did not show multicollinearity, as none of the condition indices exceeded a threshold of $15 .{ }^{33}$ None of the standardised residuals was $>3$, indicating that the models were accurate reflections of the data. ${ }^{33}$ None of the cases in the analysis exerted an undue influence on the final models, based on Mahalanobis' distances $(\mathrm{p}<0.001)^{32}$ and Cook's distances $(\mathrm{D}<\mathrm{l}) .^{33}$

\section{RESULTS}

\section{Sample properties}

A complete cognitive examination was available for 461 of the patients. Table 1 summarises the baseline demographic and background characteristics.

\section{Cognitive factors}

The factor analyses showed a three-factor solution for the cognitive variables, and table 2 shows the included variables and factor loadings.

The attention measures from the CDR, with the exception of response accuracy on the choice reaction time task, loaded on the first factor, as well as constructional praxis from the ADAS-cog. The highest-loading single variable was the number of correct detections on the digit vigilance task. The factor was judged to be mostly a measure of the attentional function vigilance, given that most of the variables required sustained attention towards some target stimulus followed by a manual response. Selective attention was also important, given that the patients had to ignore some stimuli while responding to others. Thus, the factor was named "attention".

Four variables on the ADAS-cog, which were empirically judged by the test administrator on various aspects of cognitive performance, loaded on the second factor. The variables were judgements of word-finding difficulty, spoken language ability, comprehension and the ability to understand and remember test instructions. This factor was named "verbal interaction", factor, given that these variables were based on the examiner's subjective impressions of different aspects of verbal interaction with the patient.

The third factor was more heterogeneous, with its five variables sharing a language component. Verbal memory, confrontation naming, the serial 7 task from MMSE and verbal fluency loaded on this factor. The variables had lower loadings than those in the other factors, reflecting the larger heterogeneity of the third factor. This factor was named "verbal cognition", as all the included variables shared a language component; although attentional components, memory and basic naming ability were also associated, they contributed less. For all the cognitive factor scores, higher scores indicate worse performance.

Table 1 Descriptive statistics of patients $(n=461)$

$\begin{array}{ll}\text { Age (SD) in years } & 72.5(6.6) \\ \text { Sex, } \mathrm{n}(\%) & \\ \quad \text { Male } & 308(66.8) \\ \quad \text { Female } & 153(33.2) \\ \text { Modified Hoehn and Yahr stage } & 2.7(0.8) \\ \text { UPDRS part III (motor score) } & 32.7(13.7) \\ \text { Time since diagnosis of dementia, years } & 2.3(1.5) \\ \text { Time since diagnosis of Parkinson's disease, } & \\ \text { years } & 9.8(5.6) \\ \text { MMSE score } & 19.8(3.5)\end{array}$

MMSE, Mini-Mental State Examination; UPDRS, Unified Parkinson's Disease Rating Scale.

Values are mean (SD) unless specified.
Table 2 Principal component analysis with varimax rotation of the cognitive variables

\begin{tabular}{|c|c|c|c|}
\hline \multirow[b]{2}{*}{ Rotated component matrix } & \multicolumn{3}{|c|}{ Component } \\
\hline & Attention & $\begin{array}{l}\text { Verbal } \\
\text { interaction }\end{array}$ & $\begin{array}{l}\text { Verbal } \\
\text { cognitive }\end{array}$ \\
\hline Digit vigilance-correct detections & 0.813 & 0.169 & 0.131 \\
\hline \multirow{2}{*}{$\begin{array}{l}\text { Choice RT } \log _{10} \text { corrected } \\
\text { Digit vigilance - speed of } \\
\text { detections }\end{array}$} & 0.795 & 0.211 & 0.175 \\
\hline & 0.751 & - & 0.222 \\
\hline \multirow{2}{*}{$\begin{array}{l}\text { Simple RT } \log _{10} \text { corrected } \\
\text { Digit vigilance-false alarms }\end{array}$} & 0.711 & - & 0.226 \\
\hline & 0.564 & 0.122 & - \\
\hline Constructional praxis & 0.509 & 0.151 & 0.334 \\
\hline Word-finding difficulty & - & 0.865 & - \\
\hline Spoken language ability & 0.109 & 0.862 & - \\
\hline Comprehension & 0.235 & 0.805 & 0.181 \\
\hline Remembering test instructions & 0.397 & 0.564 & 0.280 \\
\hline Naming objects/fingers & - & - & 0.720 \\
\hline $\begin{array}{l}\text { Letter fluency: total correct } \\
\text { responses }\end{array}$ & 0.295 & 0.134 & 0.638 \\
\hline \multirow{2}{*}{$\begin{array}{l}\text { Serial } 7 \text { 's as a test of attention } \\
\text { and calculation } \\
\text { Word recall }\end{array}$} & 0.131 & - & 0.602 \\
\hline & 0.364 & 0.266 & 0.562 \\
\hline Word recognition & 0.162 & 0.197 & 0.546 \\
\hline \multicolumn{4}{|c|}{$\begin{array}{l}\text { Extraction method: principal component analysis. } \\
\text { Rotation method: varimax with Kaiser normalisation. } \\
\text { Values in bold represent factor loadings }>0.5 \text {. } \\
\text { - Indicate factor loadings }<0.1 \text {. }\end{array}$} \\
\hline
\end{tabular}

\section{ADL factors}

Three factors were identified for the ADCS-ADL scale. Table 3 shows the included variables and factor scores.

The first factor was judged to be a basic physical ADL factor, with actions such as getting dressed, bathing and toileting loading highest. This factor was designated "physical ADL".

The tasks loading on the second factor were domestic chores, with the preparation of a meal and the use of household appliances loading highest. Thus, the factor was defined "domestic chores" or "instrumental ADL". However, the statistical distribution of scores on this factor was

Table 3 Principal component analysis with varimax rotation of the activities of daily living scale

\begin{tabular}{llll}
\hline & \multicolumn{2}{l}{ Component } & \\
\cline { 2 - 4 } $\begin{array}{lll}\text { Rotated component } \\
\text { matrix }\end{array}$ & $\begin{array}{l}\text { Physical } \\
\text { ADL }\end{array}$ & $\begin{array}{l}\text { Instrumental } \\
\text { ADL }\end{array}$ & $\begin{array}{l}\text { Social } \\
\text { orientation } \\
\text { ADL }\end{array}$ \\
\hline Getting dressed & $\mathbf{0 . 7 9 4}$ & 0.232 & 0.138 \\
Bathing & $\mathbf{0 . 7 6 3}$ & 0.243 & 0.144 \\
Toileting & $\mathbf{0 . 7 3 4}$ & 0.220 & - \\
Grooming & $\mathbf{0 . 6 8 6}$ & 0.204 & 0.250 \\
Walking & $\mathbf{0 . 6 4 7}$ & 0.302 & - \\
Selecting clothes & $\mathbf{0 . 6 0 4}$ & 0.202 & 0.169 \\
Eating & $\mathbf{0 . 6 0 2}$ & 0.145 & 0.160 \\
Travel & $\mathbf{0 . 5 3 8}$ & 0.386 & 0.210 \\
Meal or snack & 0.230 & $\mathbf{0 . 7 7 2}$ & 0.154 \\
Household appliance & 0.238 & $\mathbf{0 . 7 7 0}$ & 0.242 \\
Beverage & 0.345 & $\mathbf{0 . 7 3 7}$ & 0.116 \\
Clearing dishes & 0.304 & $\mathbf{0 . 6 7 3}$ & - \\
Disposing of garbage & 0.280 & $\mathbf{0 . 6 2 1}$ & 0.254 \\
Talking about current & 0.104 & 0.225 & $\mathbf{0 . 7 5 9}$ \\
events & 0.150 & 0.121 & $\mathbf{0 . 7 5 6}$ \\
Watching television & 0.116 & - & 0.698 \\
Conversation & - & 0.129 & $\mathbf{0 . 6 3 4}$ \\
Reading & 0.244 & 0.273 & $\mathbf{0 . 5 4 1}$ \\
Keeping appointments & & & \\
\hline
\end{tabular}

$A D L$, activities of daily living.

Extraction method: principal component analysis.

Rotation method: varimax with Kaiser normalisation.

Values in bold represent factor loadings $>0.5$.

-Indicate factor loadings $<0.1$. 
extremely bimodal. This would have precluded the use of parametric statistics requiring normally distributed data. Given that some patients were living in nursing homes with limited options for independent use of household appliances or general use of kitchen facilities, we excluded this factor from further analysis.

Tasks associated with social interaction as well as reading and watching TV loaded on the third factor. This factor was called "social orientation ADL".

\section{Interrelationship among ADL, cognitive and motor scores}

Table 4 shows Pearson's correlation coefficients among the cognitive factor scores, total ADL score, basic ADL score, social ADL score and UPDRS-III motor score.

Most of the correlations, although statistically significant, were weak. However, the correlations between attention and total ADL score and attention and physical ADL score approached moderate strength. UPDRS-III motor score was moderately correlated with physical ADL and approached a moderate correlation with total ADL score.

Three separate sequential regression analyses were conducted, with total ADL score, physical ADL score, and social orientation ADL score as dependent variables. For each analysis, age, sex and years of completed education were entered first, followed by UPDRS-III motor score, the two non-attentional cognitive factor scores and finally the attention score.

Table 5 shows the results of the sequential regression at each of the four steps, where total ADL score is the dependent variable. The model was considerably improved at each step of the analysis, as shown by the highly significant $\mathrm{R}^{2}$ changes. Adding attention as a predictor in step 4 increased the explained variance by $12 \%$. The total explained variance was $38 \%$ at step 4, with all predictors included in the equation. At step 4, attention was the strongest predictor of total ADL score, and all the independent variables were major predictors.

Table 6 shows the results of a sequential regression analysis using physical ADL score as the dependent variable. At each step $\mathrm{R}^{2}$ increased significantly, and at the final step $37 \%$ of the variance in physical ADL score was explained when all the independent variables were entered in the equation. Total UPDRS-III motor score was the strongest predictor, followed by attention.

Table 7 shows the results of a sequential regression analysis using social orientation ADL score as the dependent variable.

All the models were relevant, with a marked increase in $\mathrm{R}^{2}$ at each step and with $20 \%$ of the variance in social orientation ADL score explained at the final step. However, at steps 3 and 4, UPDRS-III was no longer an important predictor of social orientation ADL score. Verbal interaction was most strongly related to social orientation ADL, followed by attention and verbal cognition.

\section{DISCUSSION}

Our findings support the main hypothesis of this study that attentional deficit is related to patients' performance in ADL. Attention contributed to the prediction of physical ADL skills such as bathing, eating and getting dressed, as well as social interaction skills such as participating in conversations, keeping appointments, watching TV and reading. The effects of attention were still present after controlling for sex, age, educational level, motor functions and other aspects of cognitive functions, indicating that the effects of attention were not simply a reflection of general cognitive or motor status. Thus, given the clinical importance of ADL, these results show the prognostic significance of attention deficits in patients with PDD.

The main strengths of the study are the large and welldescribed sample of patients with PDD from multiple clinics in different countries, the extensive measures of different aspects of cognition, including attention, and a validated measure of ADL.

Perhaps the most difficult aspect of the study is the precise content of the attention factor and its relationship with other cognitive variables. The variable with the highest factor loading on the attention factor was response accuracy on a digit vigilance test, measuring ability to correctly detect and respond to a stimulus matching a target stimulus, while ignoring non-matching stimuli. The second highest loading measure was choice reaction time. The factor solution closely replicates a similar factor analysis with patients with DLB, ${ }^{8}$ where the same CDR measures were used. All variables contributing to the attention factor required a motor response and monitoring of external visual stimuli. Although we controlled for motor functions, it could be argued that the attention factor could still be influenced by motor speed. However, given that the highest loading variable on this factor is an accuracy score not dependent on simple motor reaction time and the very low correlation of 0.148 between the attention factor score and total motor score on the UPDRS-III, this seems unlikely. The attention factor seemed mostly to include functions related to sustained attention (vigilance) and attentional focus, while not being solely a strict measure of vigilance as defined by Parasuraman, ${ }^{15}$ owing to the shorter duration of the CDR tests than typical vigilance tasks. Cognitive speed could explain some of the variability of the attention factor. However, it has been shown in patients with Parkinson's disease that prolonged simple reaction time may reflect deficits of focused attention, ${ }^{34}$ and that even complex attentional control functions probably depend on cognitive speed..$^{35}$ Thus, we do not see a justification for correcting for simple reaction time.

The factor verbal cognition was more heterogeneous. Both letter fluency and the serial 7 task from MMSE, which loaded on this factor, are tests considered to require executive

\begin{tabular}{|c|c|c|c|c|c|c|}
\hline \multirow[b]{2}{*}{ Measure } & \multicolumn{6}{|c|}{ Correlation coefficient } \\
\hline & $\begin{array}{l}\text { Total ADL } \\
\text { score (DV) }\end{array}$ & $\begin{array}{l}\text { Physical } \\
\text { ADL }\end{array}$ & $\begin{array}{l}\text { Social } \\
\text { ADL }\end{array}$ & Aftention & $\begin{array}{l}\text { Verbal } \\
\text { interaction }\end{array}$ & $\begin{array}{l}\text { Verbal } \\
\text { cognitive }\end{array}$ \\
\hline Physical ADL & 0.874 & & & & & \\
\hline Social ADL & 0.701 & 0.445 & & & & \\
\hline Aftention & -0.355 & -0.359 & -0.201 & & & \\
\hline Verbal interaction & -0.243 & -0.208 & -0.280 & 0.000 & & \\
\hline Verbal cognitive & -0.286 & -0.182 & -0.239 & 0.000 & 0.000 & \\
\hline UPDRS-III motor & -0.374 & -0.469 & -0.133 & 0.148 & 0.158 & 0.078 \\
\hline
\end{tabular}


Table 5 Sequential regression with total activities of daily living score as the outcome

\begin{tabular}{|c|c|c|c|c|c|c|}
\hline Step & Variable & $\mathrm{R}^{2}$ & $R^{2}$ change & $F$ change ${ }^{\star \star}$ & $\beta$ & p Value \\
\hline \multirow[t]{4}{*}{1} & & 0.06 & 0.06 & 8.76 & & \\
\hline & Age & & & & -0.19 & $<0.001$ \\
\hline & Sex & & & & 0.10 & 0.032 \\
\hline & Education & & & & 0.14 & 0.003 \\
\hline \multirow[t]{5}{*}{2} & & 0.18 & 0.12 & 68.75 & & \\
\hline & Age & & & & -0.15 & $<0.001$ \\
\hline & Sex & & & & 0.10 & 0.021 \\
\hline & Education & & & & 0.13 & 0.002 \\
\hline & UPDRS-III motor & & & & -0.35 & $<0.001$ \\
\hline \multirow[t]{7}{*}{3} & & 0.26 & 0.08 & 26.06 & & \\
\hline & Age & & & & -0.11 & $<0.001$ \\
\hline & Sex & & & & 0.10 & 0.008 \\
\hline & Education & & & & 0.05 & 0.014 \\
\hline & UPDRS-III motor & & & & -0.31 & 0.227 \\
\hline & Verbal interaction & & & & -0.19 & $<0.001$ \\
\hline & Verbal cognitive & & & & -0.24 & $<0.001$ \\
\hline \multirow[t]{8}{*}{4} & & 0.38 & 0.12 & 80.90 & & \\
\hline & Age & & & & -0.09 & 0.018 \\
\hline & Sex & & & & 0.17 & $<0.001$ \\
\hline & Education & & & & 0.11 & 0.008 \\
\hline & UPDRS-III motor & & & & -0.26 & $<0.001$ \\
\hline & Verbal interaction & & & & -0.20 & $<0.001$ \\
\hline & Verbal cognitive & & & & -0.23 & $<0.001$ \\
\hline & Aftention & & & & -0.35 & $<0.001$ \\
\hline
\end{tabular}

attentional control. These tests also loaded weakly on the attention factor. The most obvious differences between these tasks and the tasks contributing to the attention factor are the executive control demands, the verbal component, the lack of monitoring of external stimuli and the response modality being speech rather than a simple motor response using the dominant hand. The attentional demands of this factor are of a more executive nature, requiring internal control rather than monitoring of external events. The attentional components of this factor indicate that we should be careful not to treat the attention construct as a single entity. However, as the CDR tests are designed to assess attention independently of working memory, the attentional factor can be seen as a pure assessment of attention, whereas the attentional tests that involve working memory loaded separately, supporting this differentiation.

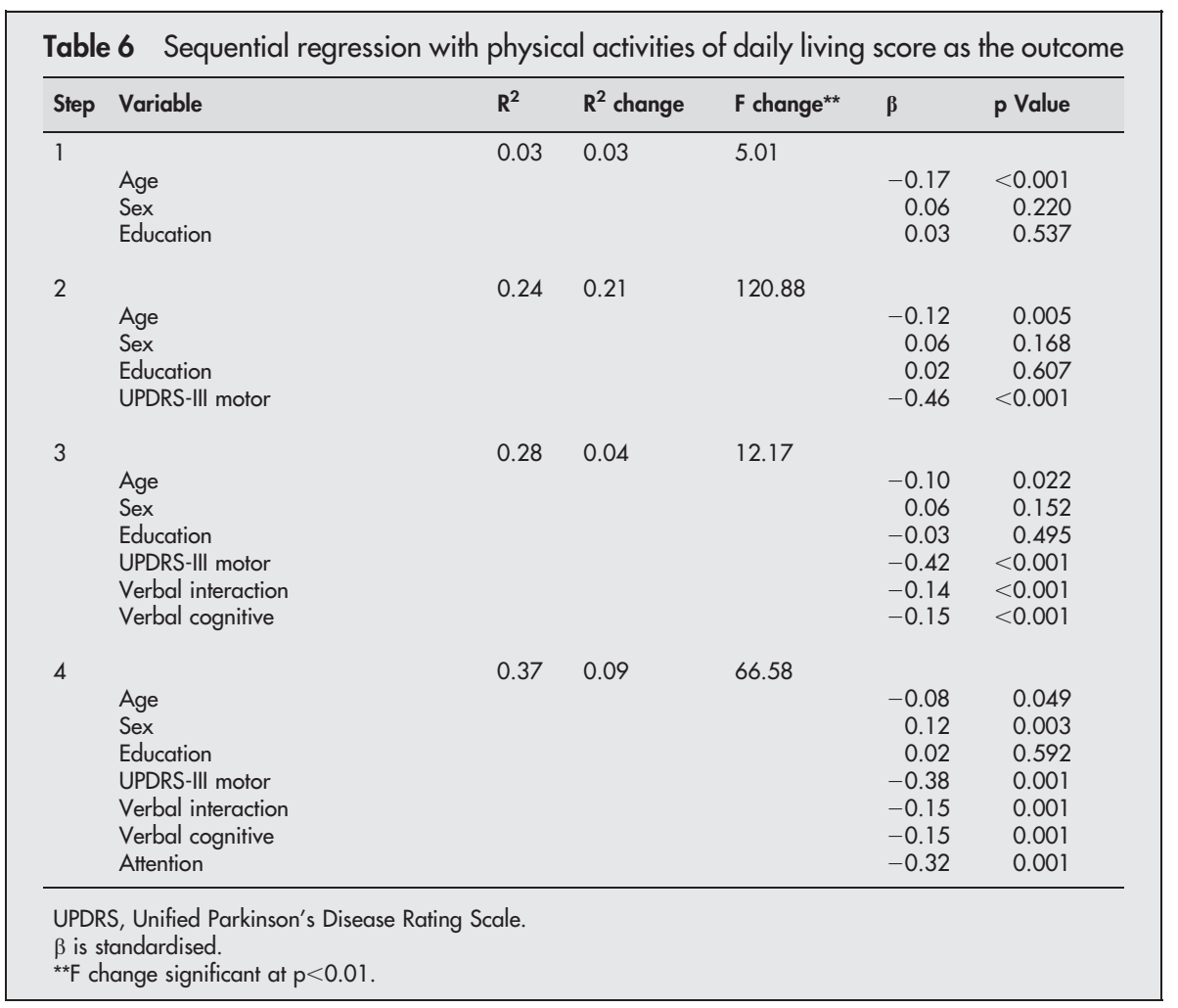


Table 7 Sequential regression with social orientation activities of daily living score as the outcome

\begin{tabular}{|c|c|c|c|c|c|c|}
\hline Step & Variable & $\mathbf{R}^{2}$ & $R^{2}$ change & F change ${ }^{\star *}$ & $\beta$ & p Value \\
\hline \multirow[t]{4}{*}{1} & & 0.04 & 0.04 & 5.67 & & \\
\hline & Age & & & & -0.06 & 0.194 \\
\hline & Sex & & & & 0.03 & 0.577 \\
\hline & Education & & & & 0.19 & $<0.001$ \\
\hline \multirow[t]{5}{*}{2} & & 0.05 & 0.01 & 7.53 & & \\
\hline & Age & & & & -0.04 & 0.340 \\
\hline & Sex & & & & 0.03 & 0.574 \\
\hline & Education & & & & 0.19 & $<0.001$ \\
\hline & UPDRS-III motor & & & & -0.13 & 0.006 \\
\hline \multirow[t]{7}{*}{3} & & 0.15 & 0.10 & 27.20 & & \\
\hline & Age & & & & -0.02 & 0.687 \\
\hline & Sex & & & & 0.03 & 0.548 \\
\hline & Education & & & & 0.12 & 0.012 \\
\hline & UPDRS-III motor & & & & -0.07 & 0.095 \\
\hline & Verbal interaction & & & & -0.27 & $<0.001$ \\
\hline & Verbal cognitive & & & & -0.20 & $<0.001$ \\
\hline \multirow[t]{8}{*}{4} & & 0.20 & 0.05 & 26.58 & & \\
\hline & Age & & & & -0.01 & 0.912 \\
\hline & Sex & & & & 0.07 & 0.121 \\
\hline & Education & & & & 0.16 & 0.001 \\
\hline & UPDRS-III motor & & & & -0.04 & 0.331 \\
\hline & Verbal interaction & & & & -0.27 & $<0.001$ \\
\hline & Verbal cognitive & & & & -0.19 & $<0.001$ \\
\hline & Aftention & & & & -0.23 & $<0.001$ \\
\hline
\end{tabular}

Our study shows that attentional dysfunction may be one of the primary cognitive factors associated with functional impairment in patients with PDD. Several implications can be drawn from this finding. More work should be carried out on the nature of attentional deficits in PDD, as several theoretical issues remain. Although earlier neuropsychological work on PDD focused on dopaminergic depletion and frontal, executive dysfunctions, ${ }^{36}$ more interest has recently been directed towards impairment in cholinergic ${ }^{38}{ }^{39}$ and noradrenergic pathways. $^{40}{ }^{41}$ The recent staging of Parkinson's disease proposed by Braak et al ${ }^{42}$ indicate that noradrenergic and cholinergic networks related to control of arousal and vigilance are affected early in Parkinson's disease. Perhaps most important in this regard is the nucleus of Meynert in the basal forebrain. This nucleus has large cholinergic projections to the cortex and is part of an important afferent regulatory system of the cortex, affecting arousal and selective attention. ${ }^{43}$ This nucleus has been proposed as central to the fluctuating level of consciousness seen in patients with $\mathrm{DLB}^{44}$ and may contribute to attentional deficits in those with PDD. Although the nucleus of Meynert is also affected in patients with Alzheimer disease, the cholinergic deficit seems to be more severe in those with PDD. $^{38}{ }^{39}$

Thus, a larger cholinergic deficit in PDD than Alzheimer's disease, may explain the improvement of attentional functions under treatment with rivastigmine in $\mathrm{DLB}^{45}$ and PDD. ${ }^{22}{ }^{28}$ In a recent study, ADL, attention and other cognitive measures improved, ${ }^{22}$ and patients with the most severe attention deficits responded best to rivastigmine. ${ }^{46}$ We believe that our findings indicate that attention is of fundamental importance for ADL performance in PDD. A practical implication is that we could more often use a test of attention in diagnosing cognitive impairment and treatment efficacy in patients with PDD. A standard computer-based vigilance test with adequate norms could be used, as digit vigilance accuracy loaded most strongly on our attention factor.
The effect of impaired attention may be mediated by the known attentional requirements of complex motor tasks ${ }^{10}$ and of a wide range of cognitive processes. ${ }^{14}$ There may also be a direct effect of attentional deficits on ADL. Further studies are justified to explore whether positive effects on ADL and cognition under treatment with rivastigmine in patients with $\mathrm{PDD}^{22}$ are mediated by an improvement in attention.

\section{Authors' affiliations}

K Bronnick, U Ehrt, D Aarsland, Psychiatric Clinic, Stavanger University Hospital, Stavanger, Norway

M Emre, Department of Neurology, Faculty of Medicine, Istanbul University, Istanbul, Turkey

P P De Deyn, Department of Neurology, General Hospital Middelheim, Antwerpen, Belgium

K Wesnes, Cognitive Drug Research Ltd, Oxon, UK

S Tekin, Novartis Pharmaceuticals, East Hanover, New Jersey, USA

Funding: The study was sponsored by Novartis Pharmaceuticals, USA. KSB received financial support from the Norwegian Research Council.

Competing interests: None declared.

\section{REFERENCES}

1 Aarsland D, Zaccai JCB. A systematic review of prevalence studies of dementia in Parkinson's disease. Mov Disord 2005;20:1255-63.

2 Aarsland D, Andersen K, Larsen JP, et al. Prevalence and characteristics of dementia in Parkinson disease: an 8-year prospective study. Arch Neurol 2003,60:387-92.

3 Louis ED, Tang MX, Cote L, et al. Progression of parkinsonian signs in Parkinson's disease. Arch Neurol 1999:56:334-7.

4 Marras C, Rochon P, Lang AE. Predicting motor decline and disability in Parkinson's disease. Arch Neurol 2002;59:1724-8.

5 Schrag A, Jahanshahi M, Quinn N. What contributes to quality of life in patients with Parkinson's disease? J Neurol Neurosurg Psychiatry 2000;69:308-12.

6 Aarsland D, Larsen JP, Karlsen K, et al. Mental symptoms in Parkinson's disease are important contributors to caregiver distress. Int $J$ Geriatr Psychiatry 1999; 14:866-74 
7 Wancata J, Benda N, Meise U, et al. Non-cognitive symptoms of dementia in nursing homes: frequency, course and consequences. Soc Psychiatry Psychiatr Epidemiol 2003;38:637-43.

8 Ballard CG, Aarsland D, McKeith I, et al. Fluctuations in attention: PD dementia vs DLB with parkinsonism. Neurology 2002;59:1714-20.

9 Woollacott M, Shumway-Cook A. Attention and the control of posture and gait: a review of an emerging area of research. Gait Posture 2002;16:1-14.

10 Rowe J, Stephan KE, Friston K, et al. Attention to action in Parkinson's disease: impaired effective connectivity among frontal cortical regions. Brain 2002; 125(Pt 2):276-89.

11 Zgaljardic DJ, Borod JC, Foldi NS, et al. A review of the cognitive and behavioral sequelae of Parkinson's disease: relationship to frontostriatal circuitry. Cogn Behav Neurol 2003;16:193-210.

12 Bouquet CA, Bonnaud V, Gil R. Investigation of supervisory attentional system functions in patients with Parkinson's disease using the Hayling task. J Clin Exp Neuropsychol 2003;25:751-60.

13 Poliakoff E, O'Boyle DJ, Moore AP, et al. Orienting of attention and Parkinson's disease: tactile inhibition of return and response inhibition. Brain 2003; 126(Pt 9):2081-92.

14 Parasuraman R. The attentive brain: issues and prospects. In: Parasuraman R, ed. The attentive brain. Cambridge: MIT Press, 1998:3-13.

15 Parasuraman R. Brain systems of vigilance. In: Parasuraman R, ed. The attentive brain. Cambridge, MA: MIT Press, 1998.

16 Foltynie T, Brayne CE, Robbins TW, et al. The cognitive ability of an incident cohort of Parkinson's patients in the UK. The CamPalGN study. Brain 2004; 127(P+ 3):550-60

17 Muslimovic D, Post B, Speelman JD, et al. Cognitive profile of patients with newly diagnosed Parkinson disease. Neurology 2005;65:1239-45.

18 Sharpe MH. Auditory attention in early Parkinson's disease: an impairment in focused attention. Neuropsychologia 1992;30:101-6.

19 Cahn DA, Sullivan EV, Shear PK, et al. Differential contributions of cognitive and motor component processes to physical and instrumental activities of daily living in Parkinson's disease. Arch Clin Neuropsychol 1998;13:575-83.

20 Maeshima S, Itakura T, Nakagawa $M$, et al. Visuospatial impairment and activities of daily living in patients with Parkinson's disease: a quantitative assessment of the cube-copying task. Am J Phys Med Rehabil 1997:76:383-8.

21 Ballard CG, Walker M, O'Brien J, et al. The characterisation and impact of "fluctuating" cognition in dementia with Lewy bodies and Alzheimer's disease. Int J Geriatr Psychiatry 2001;16:494-8

22 Emre M, Aarsland D, Albanese A, et al. Rivastigmine for dementia associated with Parkinson's disease. N Engl J Med 2004;351:2509-18.

23 McKeith I, Mintzer J, Aarsland D, et al. Dementia with Lewy bodies. Lancet Neurol 2004;3:19-28.

24 American Psychiatric Association. Diagnostic and statistical manual of mental disorders, 4th edn. Washington DC: American Psychiatric Association, 1994

25 Folstein MF, Folstein SE, McHugh PR. "Mini-mental state". A practical method for grading the cognitive state of patients for the clinician. J Psychiatr Res 1975; 12:189-98.

26 Rosen WG, Mohs RC, Davis KL. A new rating scale for Alzheimer's disease. Am J Psychiatry 1984;141:1356-64.

27 Delis DC, Kaplan E, Kramer JH. Delis-Kaplan executive function system. San Antonio, TX: Psychological Corporation, 2001.

28 Wesnes KA, McKeith I, Edgar C, et al. Benefits of rivastigmine on attention in dementia associated with Parkinson disease. Neurology 2005;65:1654-6.
29 Simpson PM, Surmon DJ, Wesnes KA, et al. The Cognitive Drug Research computerized Assessment System for demented patients: a validation study. Int J Geriatr Psychiatry 1991;6:95-102.

30 Galasko D, Bennett D, Sano $M$, et al. An inventory to assess activities of daily living for clinical trials in Alzheimer's disease. The Alzheimer's Disease Cooperative Study. Alzheimer Dis Assoc Disord 1997; 11(Suppl 2):S33-9.

31 Fahn SRLE, Committee. MotUD. Unified Parkinson's Disease Rating Scale. In: Fahn S, Marsden CD, Calne DMAL, eds. Recent development in Parkinson's disease. Florham Park, NJ: MacMillan Health Care Information, 1987:153-63.

32 Tabachnick BG, Fidell LS, eds. Using multivariate statistics, 4th edn. Boston, MA: Allyn and Bacon, 2001.

33 Hair JF, Anderson RE, Tatham RL, et al, eds. Multivariate data analysis, 5th edn. Upper Saddle River, NJ: Prentice Hall, 1998.

34 Goodrich S, Henderson L, Kennard C. On the existence of an attentiondemanding process peculiar to simple reaction time: converging evidence from Parkinson's disease. Cogn Neuropsychol 1989;6:309-31.

35 Salthouse TA. Relation of task switching to speed, age, and fluid intelligence. Psychol Aging 1998;13:445-61.

36 Lange KW, Robbins TW, Marsden CD, et al. L-dopa withdrawal in Parkinson's disease selectively impairs cognitive performance in tests sensitive to frontal lobe dysfunction. Psychopharmacology 1992; 107:394-404.

37 Levin BE, Llabre MM, Weiner WJ. Neuropsychological correlates of early Parkinson's disease: evidence for frontal lobe dysfunction. Ann N Y Acad Sci 1988;537:518-19.

38 Bohnen NI, Kaufer DI, Hendrickson R, et al. Cognitive correlates of cortical cholinergic denervation in Parkinson's disease and parkinsonian dementia. J Neurol 2006;253:242-7.

39 Bohnen NI, Kaufer DI, Ivanco LS, et al. Cortical cholinergic function is more severely affected in parkinsonian dementia than in Alzheimer disease. Arch Neurol 2003;60:1745-8.

40 Bedard MA, el Massioui F, Malapani C, et al. Attentional deficit in Parkinson's disease: partial reversibility with naphtoxazine (SDZ NVI-085), a selective noradrenergic alpha 1 agonist. Clin Neuropharmacol 1998;21:108-17.

41 Srinivasan J, Schmidt WJ. Behavioral and neurochemical effects of noradrenergic depletions with $\mathrm{N}$-(2-chloroethyl)- $\mathrm{N}$-ethyl-2-

bromobenzylamine in 6-hydroxydopamine-induced rat model of Parkinson's disease. Behav Brain Res 2004;151:191-9.

42 Braak H, Del Tredici K, Rub U, et al. Staging of brain pathology related to sporadic Parkinson's disease. Neurobiol Aging 2003;24:197-211.

43 Perry EK, Perry RH. Neurochemistry of consciousness: cholinergic pathologies in the human brain. Prog Brain Res 2004;145:287-99.

44 Walker M, Perry EK. Dementia with Lewy-bodies. A disorder of consciousness? In: Perry EK, Ashton H, Young A, eds. Neurochemistry of consciousness. Amsterdam: John Benjamins Publishing, 2002.

45 Wesnes K, McKeith I, Ferrara R, et al. Effects of rivastigmine on cognitive functions in dementia with Lewy-bodies: a randomized placebo-controlled international study using the cognitive drug research computerized assessment system. Dement Geriatr Cogn Disord 2002;13:182-92.

46 Wesnes KA, Edgar C, Thomas J, et al. Rivastigmine reduces the attentional deficit in dementia associated with Parkinson's disease and treatment response is dependent on the initial severity of the deficits. Int Psychogeriatr 2005; 17(Suppl 2):263-4. 